\title{
Evaluation of Neonicotinoid Residues in Hive Products from Selected Counties in Kenya
}

Protus Mulati $^{1 *}$, Esther Kitur ${ }^{1}$, Catherine Taracha ${ }^{1}$, Justus Kurgat ${ }^{2}$, Suresh Raina ${ }^{2}$ and Janet Irungu ${ }^{2}$

${ }^{1}$ Department of Environmental Sciences, Kenyatta University, PO Box 43844, Nairobi, Kenya

${ }^{2}$ International Center of Insect Physiology and Ecology (ICIPE), PO Box 30772, 00100, Nairobi, Kenya

\begin{abstract}
The presence of neonicotinoid residues in bee hive products and the wide spread human consumption of these products is already a food safety problem in Kenya. This study aims to find out the concentration of neonicotinoid residues in bee hive products from Kiambu and Nairobi counties. Neonicotinoid residues were extracted from two hive products (honey and pollen) using modified Quick Cheap Rugged Safe (QUECHERS) method. Liquid chromatography coupled with mass spectrometry (LC-MS/MS) was used to identify and quantify the specific residues present. Three neonicotinoid residues (acetamiprid, thiamethoxam and imidacloprid) were detected in pollen and honey with the levels of contamination dependent on the location of the apiary. Our results indicate that pollen was the most contaminated with some of the residues detected exceeding the maximum residue limits (MRL) accepted in apicultural products whereas all the levels of residues detected in honey were all below the MRL. Specifically, the concentrations of thiamethoxa $\mathrm{m}$ detected in pollen from apiaries located in horticultural farms were more than 4-fold higher than the acceptable MRL in apicultural products. In addition to experimental analysis, during a field survey a total of 72 households were involved in a cross- sectional survey to assess the pesticides usage and frequency of application on cultivated crops around apiaries. Structured pre-tested questionnaires were administered through personal interviews and focused group discussion among beekeepers in the study site. The study revealed that pesticides used in the region include carbamates $(32.4 \%)$, pyrethroids $(14.6 \%)$, neonicotinoids $(14.4 \%)$, herbicides $(15.7 \%)$, fungicides $(1.4 \%)$, acaricides $(5.6 \%)$ and organophosphates (14.5\%). The study also showed that $26.4 \%$ of respondents used carbaryl carbamates, $13.2 \%$ use Karate, $12 \%$ thiamethoxam and $7.4 \%$ dichlorvos. On the frequency of application, $86 \%$ of respondents used pesticides every week, $12.5 \%$ fortnightly and $1.4 \%$ when available. The presence of neonicotinoid residues in bee hive products suggests that neonicotinoids poses a potential food safety problem in the beekeeping industry hence there is a need for additional long-term monitoring.
\end{abstract}

Keywords: Neonicotinoid residues; Bee health; Hive products; Pesticides; LC-MS/MS

\section{Introduction}

Neonicotinoids are relatively new systemic agricultural insecticides that are widely used as seed dressing to flowering crops [1] due to their high efficacy, high selectivity, plant systemicity thus efficient against a wide range of pests over a long period and when applied in small quantities, and have versatile applications. Neonicotinoids have low effects to plants and animals compared to organophosphates. However, they interfere with the transmission of stimuli in insects' nervous system by causing blockage in the nercotinergic neural pathways. This pathway is more common in insects than in vertebrates, making them highly toxic to insects. The recent widespread use of neonicotinoids and its possible translocation to pollen and nectar, the main food sources for bees, has raised concerns for possible detrimental impact on these beneficial insects. These chemicals have been associated with colony collapse disorder in the western countries [2] leading to some temporary ban of three neonicotinoids (clothianidin, thiamethoxam and imidacloprid) as seed treatments for use on crops attractive to bees in the European Union [3] and a policy introduced to reduce the use of the same three insecticides as seed treatments for some crops. However, significant knowledge gaps and controversy remain as to whether such restrictions are justified. Globally, neonicotinoids use has motivated environmentalists, policy makers, farmers, pesticide companies and beekeepers to engage in an endless debate about whether or not a ban on pesticides would save the bees. When neonicotinoids were first used, beekeepers described different disorders and signs ranging from, disoriented bees not returning to the hive, bees gathered close together in small groups on the ground, abnormal foraging behaviour, the occurrence of massive bee losses in season, queen bee losses, increased sensitivity to diseases and colony decline [4]. Unfortunately, the use of neonicotinoids along with other pesticides is on the rise in most African countries especially Kenya due to the need to boost agriculture and food production to sustain the ever-increasing population and reach the food security envisaged in the global sustainable development goals. In addition, unfavorable weather conditions, inadequate rainfall and poor soils make management of agricultural farms more difficult, compelling farmers to use and apply more pesticides [5]. A visit by honey bees to agro-chemically treated flowering plants exposes them to a mixture of pesticides, and the contaminated pollen and nectar is then transferred into bee hives [6].

However, the status of pesticide residues on bee hive products (honey and bee bread (pollen) is scanty or totally absent in sub-Saharan Africa yet such knowledge is important to safeguard human health and conserve pollinators. Beehive products such as honey are widely consumed as food and medicine and their contamination may pose serious health hazards. Honey as a natural product is considered to be free from any pesticides, heavy metals and radioactive materials. However chemical residues have been reported by several investigators

*Corresponding author: Protus Mulati, Department of Environmental Sciences, Kenyatta University, PO Box 43844, Nairobi, Kenya, Tel: +254723961938; E-mail: wanjaprot06@yahoo.com

Received June 18, 2018; Accepted July 27, 2018; Published July 30, 2018

Citation: Mulati P, Kitur E, Taracha C, Kurgat J, Raina S, et al. (2018) Evaluation of Neonicotinoid Residues in Hive Products from Selected Counties in Kenya. J Environ Anal Toxicol 8: 577. doi: 10.4172/2161-0525.1000577

Copyright: (C) 2018 Mulati P, et al. This is an open-access article distributed under the terms of the Creative Commons Attribution License, which permits unrestricted use, distribution, and reproduction in any medium, provided the original author and source are credited. 
Citation: Mulati P, Kitur E, Taracha C, Kurgat J, Raina S, et al. (2018) Evaluation of Neonicotinoid Residues in Hive Products from Selected Counties in Kenya. J Environ Anal Toxicol 8: 577. doi: 10.4172/2161-0525.1000577

Page 2 of 7

[7-17]. However, to date, only few studies have been carried out to monitor pesticide residues in honey produced from Africa [18]. The presence of the cumulative effects of toxins and pesticide residues in honey cannot only have adverse effects on bees and humans but they can also decrease the quality of honey and devalue its beneficial properties. This implies that there is need to monitor the presence of neonicotinoids residues in hive products to assess the potential health risks and to ensure that the honey quality whether for human food or as bee food is not compromised. The present study aims to investigate beehive matrix contamination by neonicotinoids in two different landscape structures characterized by forested and cultivated landscape. The results provide some insights in the safety of honey from Kenya and some baseline information for more in-depth future studies on other compounds of hive matrix in relation to honey bee colony loses.

\section{Methodology Sample Collection}

Prior to undertaking the study in each of the apiaries, informed consents were obtained from the owners of the honey bee colonies after explaining to them the background and the purpose of the study. The participants in this study were mainly small holder farmers working individually or as part of a beekeeper's association group.

Samples of honey and pollen were collected in Kiambu and Nairobi Counties located between latitude $1^{\circ} 20^{\prime \prime}$ S $-0^{\circ} 55^{\prime \prime} \mathrm{N}$ and longitude $36^{\circ} 30^{\prime \prime} \mathrm{E}-37^{\circ} 20^{\prime \prime} \mathrm{E}$ approximately $1600 \mathrm{~m}$ above sea level (Figure 1). The study sites consisted of two apiaries located in forested landscapes of Ngong and Karura forest free from high levels of anthropogenic activities and seven apiaries in cultivated landscapes of Juja, Thika, Thika IPM, Gatundu, Kikuyu, Ruiru and Lari. Cultivated landscapes had large fields of crops (horticultural, coffee, vegetables, potatoes, french beans, pineapple farms and maize and beans). The nine apiaries therefore were purposively chosen. Samples were collected from only two apiaries in forested sites due to limited number of available apiaries. The choice of the apiaries from each of these sites was based on the number and the strength of active colonies present. In each of the sites, three apiaries spread apart ( $>5 \mathrm{~km}$ from each other) were randomly selected.

\section{Sample preparation and extractions}

Pesticide residues were extracted from honey samples according to the method described previously by Irungu et al. $[19,20]$. Briefly, samples weighing $5 \mathrm{~g}$ of either honey or pollen were homogenized in separate $50 \mathrm{ml}$ falcon tubes using $10 \mathrm{ml}$ of water followed by $10 \mathrm{ml}$ of acetonitrile and a mixture of QuEChERS salts. The samples were then vortexed for $1 \mathrm{~min}$ and centrifuged at 4,200 rpm for $5 \mathrm{~min}$. The supernant was filtered through hydrophilic PTFE $0.2 \mu \mathrm{m}$. and diluted at $1: 1(\mathrm{v} / \mathrm{v})$ with water and finally transferred to auto sampler vial for LC-MS/ MS for quantification.

\section{Sample analysis}

A target-residue approach, using LC-MS/MS for screening, was adapted to search for chemical contaminants against 3 neonicotinoid pesticides that were chosen based on the information obtained from the farmers and local agrochemical stores. Data analysis was carried out as previously described [20].

\section{Results}

\section{Neonicotinoid residues in honey}

Neonicotinoids residues detected in honey showed varied concentrations among the apiaries studied (Table 1). Thiamethoxam and Imidacloprid were below limits of quantification (LOQ) (0.1 ppb), in all the apiaries investigated. Acetamiprid residue concentration were detected in honey from Thika IPM $0.50 \mathrm{ppb}$, Juja $0.32 \mathrm{ppb}$ and in all other apiaries, Karura, Ngnog, Lari, Ruiru, Thika, Gathundu and Kikuyu, and were all below the LOQ (Table 1). T-test analysis showed no significant differences between acetamiprid residue in honey from Thika IPM and Juja, $\mathrm{t}=3.5206, \mathrm{df}=8$ and $\mathrm{p}=0.007839$ ). The levels of

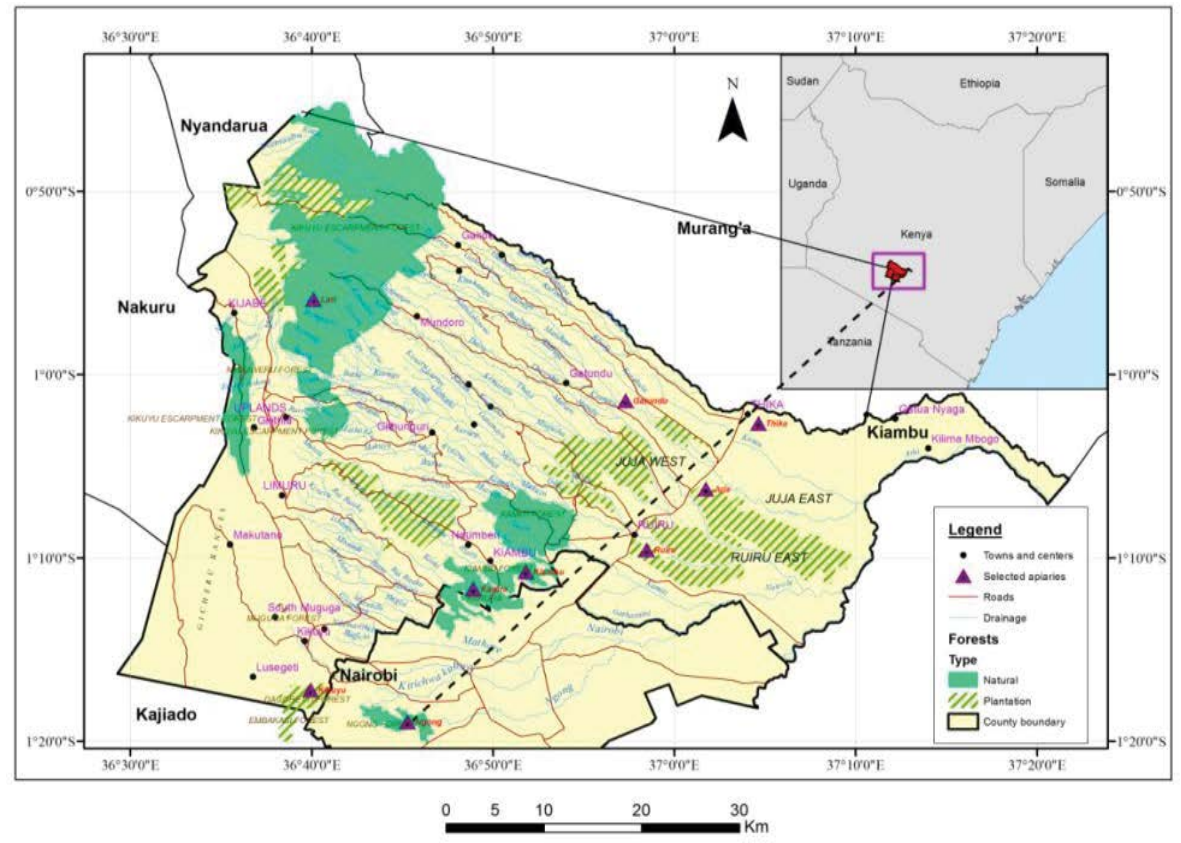

Figure 1: Map of Kenya showing sampling region Kiambu and Nairobi Counties ( $n=9$ highlighted in triangles). 
Citation: Mulati P, Kitur E, Taracha C, Kurgat J, Raina S, et al. (2018) Evaluation of Neonicotinoid Residues in Hive Products from Selected Counties in Kenya. J Environ Anal Toxicol 8: 577. doi: 10.4172/2161-0525.1000577

Page 3 of 7

thiamethoxan, imidacloprid and acetamiprid residues in honey were below the MRL levels specified in EU standards (Table 1).

\section{Neonicotinoid residues in pollen}

The concentrations of neonicotinoids residues in pollen (bee bread) ranged from levels below LOQ to levels higher than the acceptable MRL limits (Table 2). Acetamiprid residues levels were below the LOQ in all the sampled apiaries $<0.10 \mathrm{ppb}$ (Table 2). Thiamethoxan residues ranged from $0.1 \mathrm{ppb}$ to $47.80 \mathrm{ppb}$ in Thika IPM while Imidaclopid levels were up to $2.19 \mathrm{ppb}$ in Thika IPM. Thiamethoxam residues concentrations in Thika IPM were more than 4-fold higher than the acceptable levels (10 ppb according to the European standards). There was no significant differences in mean concentration of thiamethoxan in Karura and Ngong stations $(\mathrm{t}=1.3279, \mathrm{df}=1, \mathrm{p}=0.4109)$. A t-test also showed no significant differences in mean concentration between imidaclopid concentration. In Thika and Thika IPM stations, $\mathrm{t}=1.5172$, $\mathrm{df}=1$ and $\mathrm{p}=0.371$ ) (Table 2). The other apiaries where thiamethoxam was detected was in Karura forest (0.71) and Kikuyu (10.92). Imidacloprid was also detected in higher concentrations in Thika and Juja apiaries: 0.45 and $0.43 \mathrm{ppb}$ respectively but were below the EU levels.

\section{Types of pesticides used on cultivated crops}

During the survey, the study revealed that the types of pesticides used on cultivated crops around the apiaries varied during the study period (Table 1). The pesticides used can be categorized into 7 classes; carbamates, organophosphates, herbicides, acaricides, neonicotinoids, pyrethroids and fungicides (Table 2). Carbamate based pesticides were the most applied and was applied by $32.4 \%$ respondents. The other pesticides applied were pyrethroids by $14.6 \%$, neonicotinoids $14.4 \%$, organophosphates $14.5 \%$, herbicides $15.7 \%$ acaricides and $5.6 \%$ fungicides by $1.4 \%$ of the respondents (Table 1 ). The pesticides were applied mainly on coffee, maize, vegetables, tomatoes and potatoes (Table 3). The study also showed that of the $32.4 \%$ of the respondents who used carbamate based pesticides, $26.4 \%$ use carbaryl on fruits, $13.2 \%$ use karate (pyrethroids) on tomatoes, thiamethoxam (neonicotinoids) was used by $12 \%$ of the respondents on coffee and roses, while dichlorvos (organophosphates) was used by $7.4 \%$ of the respondents on potatoes. About $1.4 \%$ of the respondents did not use any pesticides at all (Table 2). The study also revealed that banned or restricted pesticides are still used in the study area. The banned carbamate (aldicarb) and organophosphate (dimethoate is used by $3.2 \%$ and $1.9 \%$ of the respondents respectively while $1.9 \%$ of the respondents use the restricted thunder (imidacloprid) and 12\% actara (thiamethoxam). In Kenya the commonly used chemicals to control thrips, cutworms and aphids from vegetables are bestox, thunder (imidacloprid) dimethoate and bulldock [21]. However, found that herbicides are rarely used in vegetable farming, while in Ghana herbicides are mostly used in vegetable farming [22]. Study by Miriti et al. in Central Kenya found out that Linuron (herbicides) and diazinon (organophosphate) recorded high levels of application percentage. A recent study by Irungu et al. [19] covering the agroecological zones in Kenya also revealed insecticides contamination in hive matrices are more common followed by herbicides. Pyrethroids and organophosphates are preferred by farmers due to their familiarity, different size packages and are affordable. Pyrethroids are also used most because they are low in toxicity to humans, mammals and birds [23].

According to WHO [24] classification, dichlorvos (Phosvit) are extremely hazardous and are applied by small percentage of farmers. Macharia et al. [25] found out that carbamates are applied by $41 \%$, followed by pyrethroids (19\%), organophosphates (16\%) and inorganics $(5 \%)$. Carbamates are used widely because they are safer to humans, and are effective on crop pests [24].

\section{Discussion}

The varied levels of neonicotinoid residues in honey from the different apiariess is attributed to the nature of the surroundings, location and distances of the apiaries from the intensive conventional horticultural/farming. Results from this study revealed that honey collected from apiaries located in agricultural field with high horticultural crops, which use pesticides, are more contaminated than honey collected in forested landscape and this is consistent with previous studies [26]. This is possibly because cultivation of these crops requires a large amount of pesticides and fertilizers as these are mainly for export, hence the need for high quantities and short maturation time. The presence of the three neonicotinoid residues, thiamethoxam, imidacloprid and acetamiprid in the honey and bee bread could also be attributed to large scale agricultural activities which are carried out in Thika IPM, Juja and Kikuyu. These regions are known to have large scale production of horticultural/Floriculture crops, French beans, beans, roses, pineapples tomatoes and vegetables and large scale coffee and tea plantations which heavily depend on pesticides. The survey data indicated that $86 \%$ of the farmers in the study sites use neonicotinoid to control pests in the coffee, tea and horticultural production. Intensive use of pesticides is used during the wet season which happens to be the season of high foraging (Table 3). Acetamiprid was the only neonicotinoid residue in honey that was found in high levels in honey samples collected from apiaries located in Thika IPM $0.5 \mathrm{ppb}$ and Juja $0.32 \mathrm{ppb}$ stations. The high levels could be attributed to the wide and versatile application of pesticides which contain acetamiprid as an

\begin{tabular}{|c|c|c|c|c|c|c|c|c|c|}
\hline \multirow{2}{*}{ Apiary/Residue } & \multicolumn{3}{|c|}{ Thiamethoxam (ppb) } & \multicolumn{3}{|c|}{ Imidacloprid (ppb) } & \multicolumn{3}{|c|}{ Acetamiprid (ppb) } \\
\hline & Detection & EU standards & $P$ Value $s$ & Detection & EU standards & p-Values & Detection & EU standards & p-Values \\
\hline Karura & $<\mathrm{LOQ}$ & 10 & - & $<\mathrm{LOQ}$ & 50 & - & 0.10 & 50 & - \\
\hline Ngong & $<L O Q$ & 10 & - & $<\mathrm{LOQ}$ & 50 & - & 0.10 & 50 & - \\
\hline Lari & $<\mathrm{LOQ}$ & 10 & - & $<\mathrm{LOQ}$ & 50 & - & 0.10 & 50 & - \\
\hline Ruiru & $<L O Q$ & 10 & - & $<L O Q$ & 50 & - & 0.10 & 50 & - \\
\hline Thika & $<\mathrm{LOQ}$ & 10 & - & $<\mathrm{LOQ}$ & 50 & - & 0.10 & 50 & - \\
\hline Thika IPM & $<L O Q$ & 10 & - & $<L O Q$ & 50 & - & 0.50 & 50 & - \\
\hline Gatund $\mathrm{u}$ & $<\mathrm{LOQ}$ & 10 & - & $<\mathrm{LOQ}$ & 50 & - & 0.10 & 50 & - \\
\hline Juja & $<\mathrm{LOQ}$ & 10 & - & $<\mathrm{LOQ}$ & 50 & - & 0.32 & 50 & \\
\hline Kikuyu & $<L O Q$ & 10 & - & $<\mathrm{LOQ}$ & 50 & - & 0.10 & 50 & 0.001 \\
\hline
\end{tabular}


Citation: Mulati P, Kitur E, Taracha C, Kurgat J, Raina S, et al. (2018) Evaluation of Neonicotinoid Residues in Hive Products from Selected Counties in Kenya. J Environ Anal Toxicol 8: 577. doi: 10.4172/2161-0525.1000577

Page 4 of 7

\begin{tabular}{|c|c|c|c|c|c|c|c|c|c|}
\hline \multirow{2}{*}{ Apiary/Residue } & \multirow{2}{*}{ Detection } & \multicolumn{2}{|c|}{ Thiamethoxam (ppb) } & \multicolumn{2}{|c|}{ Imidacloprid (ppb) } & \multicolumn{2}{|c|}{ Acetamiprid (ppb) } & \multirow{2}{*}{ EU standards } & \multirow{2}{*}{ p-Values } \\
\hline & & EU standards & P-Values & Detection & EU standards & p-Values & Detection & & \\
\hline Karura & 0.71 & 10 & - & 0.10 & 50 & - & $<\mathrm{LOQ}$ & 50 & - \\
\hline Ngong & 0.10 & 10 & - & 0.10 & 50 & - & $<\mathrm{LOQ}$ & 50 & - \\
\hline Lari & 0.10 & 10 & - & 0.10 & 50 & - & $<L O Q$ & 50 & - \\
\hline Ruiru & 0.10 & 10 & - & 0.10 & 50 & - & $<\mathrm{LOQ}$ & 50 & - \\
\hline Thika & 0.10 & 10 & - & 0.45 & 50 & - & $<L O Q$ & 50 & - \\
\hline Thika IPM & 47.80 & 10 & - & 2.19 & 50 & - & $<\mathrm{LOQ}$ & 50 & - \\
\hline Gatund u & 0.10 & 10 & - & 0.10 & 50 & - & $<\mathrm{LOQ}$ & 50 & - \\
\hline Juja & 0.10 & 10 & - & 0.43 & 50 & - & $<L O Q$ & 50 & - \\
\hline Kikuyu & 10.92 & 0.10 & - & 0.10 & 50 & - & $<\mathrm{LOQ}$ & 50 & \\
\hline
\end{tabular}

Table 2: Neonicotinoid compounds detected in pollen (bee bread) and their concentration levels in ppb at 9 apiaries.

\begin{tabular}{|c|c|c|c|}
\hline Trade name of pesticide & Classification & Crops grown near apiaries & $\%$ of respondent \\
\hline Cabaryl & Carbamate & Fruits & 26.4 \\
\hline Karate & Pyrethroid & Tomatoes & 13.2 \\
\hline Dimethoate (banned) & Organophosphate & potatoes & 1.9 \\
\hline Thiamethoxam (actara) & Neonicotinoid & Coffee/horticulture & 12 \\
\hline Metribuzin & Herbicide & Coffee & 8 \\
\hline Pyraclostrobin & Organophosphate & Coffee/roses & 1.9 \\
\hline Dichlorvos & Organophosphate & Potatoes & 7.4 \\
\hline Atrazine & Herbicide & Coffee & 1.9 \\
\hline Cypermethrin & Acaricide & Tomatoes/potatoes & 5.6 \\
\hline Carbendazim & Carbamates & Roses & 0.9 \\
\hline Mancozeb & Fungicides & Vegetables & 0.9 \\
\hline Aldicarb (banned) & Carbamate & Maize & 3.2 \\
\hline Bulldock & Pyrethroid/organophospate & Tomatoes & 0.5 \\
\hline Imidacloprid (Thunder) & Neonicotinoids & Coffee/horticulture/Maize & 1.9 \\
\hline Acetamiprid & Neonicotinoids & Coffee/horticulture & 0.5 \\
\hline Ridomil & Carbamate & Tomatoes & 0.9 \\
\hline Hexaconazole & Fungicide & Coffee/fruits & 0.5 \\
\hline Bestox & Pyrethroid & Tomatoes & 0.9 \\
\hline Antracol & Carbamate & Tomatoes & 0.5 \\
\hline Diazinon & Organophosphate & & 0.5 \\
\hline Dithane M45 & Carbamate & Tomatoes/vegetables & 0.5 \\
\hline Malathion & Organophosphate & Coffee & 2.8 \\
\hline Linuron & Herbicides & Maize & 5.8 \\
\hline \multirow[t]{2}{*}{ No pesticide use } & - & - & 1.4 \\
\hline & & & 100 \\
\hline
\end{tabular}

Table 3: Types of Pesticide used and applied on cultivated crops in the study area during the study period.

active ingredient for control of sucking insects in horticultural crops. Flowers and coffee are the main crops in Thika IPM and Juja stations. The study also found that $14.4 \%$ of the farmers indicated that they use neonicotinoid to protect their crops against the pests. The hygienic behaviour of bees and physiological susceptibility of honey bees may have influenced the concentration of acetamiprid detected (Table 3). Furthermore, bees have the ability to filter out or have catholic taste capable of diluting pesticides compounds in honey [27] and this could be responsible for the low concentration of acetamiprid detected despite its use.

Thiamethoxam and imodacloprid were detected in bee bread (pollen) from apiaries located in Thika IPM $47.80 \mathrm{ppb}$ and 2.19 ppb respectively. Other apiaries which recorded presence of these neonicotinoids were Kikuyu, Thika and Juja. Contamination of pollen may have occurred through both contact and oral exposure. Bees are often covered with contaminated pollen during foraging activities and transport chemical residues into beehives. Previous studies that investigated chemical residues in hive products have also reported a similar trend leading to some researchers concluding that pollen is the most contaminated hive products $[20,28]$. Thiamethoxam in particular is a broad spectrum systemic insecticide used in control of sucking insects in flowers, vegetables, leaf miners in coffee and for maize and beans treatments. The levels for this chemical in apicultural products that would not pose a health concern is more than 4-fold lower (10 $\mathrm{ppb})$ than the concentration reported in this study (47.8 ppb) which would therefore be considered hazardous for both human and bees consumption. The higher levels detected is not surprising considering that the region in question is dominated by both small-scale and largescale farming of horticultural crops, such as french beans, pineapples and coffee farming. Moreover, most of the farmers from this site indicated that they used thiamethoxam in their farms to control pests in coffee and horticultural farms (Table 3). In addition, the wet season sampling in this region coincided with high period of heavy pesticide spraying and application. 
Citation: Mulati P, Kitur E, Taracha C, Kurgat J, Raina S, et al. (2018) Evaluation of Neonicotinoid Residues in Hive Products from Selected Counties in Kenya. J Environ Anal Toxicol 8: 577. doi: 10.4172/2161-0525.1000577

Page 5 of 7

\section{Aspects that contributes to presence of acetamiprid in honey samples}

First, the distance/location of colonies from intensive conventional/ horticultural crops or Nature of the surroundings. The selected apiaries were located in landscape dominated by coffee, grain crops (maize and beans), vegetables and coffee plantations. Apiaries located in agricultural fields with high monoculture crops and high anthropogenic activities are more contaminated [26]. Apiaries in Thika IPM were in close proximity to rose and coffee plantations thus the higher concentration. This indicated the possibility of honeybees foraging on contaminated pollen and nectar and carrying pesticides into food chain through the hive matrix into hive products in beehives.

Second, the presence of acetamiprid insecticides in honey samples confirms actual transfer of neonicotinoid insecticides from exposed honey bees into honey. The acetamiprid acute oral toxicity; $\mathrm{LD}_{50}=14.53$ $\mu \mathrm{g} / \mathrm{bee}$ according to European commission 2011 analysis report, thus honeybees are not easily exposed to lethal doses of acetamiprid during their foraging activities and thus are able to transport acetamiprid into hives.

Third, frequency of pesticide application and use of acetamiprid. The wide and versatile application of the plant product containing acetamiprid as active ingredient which was used in control of sucking insects in horticultural crops (flowers) and leaf miners in coffee. The survey data indicated high frequency of acetamiprid application.

Fourth, the hygienic behavior of bees and physiological susceptibility of honey bees may influence the low presence or concentration of acetamiprid. It is well documented that bees have the ability to filter out or have catholic taste capable of diluting pesticide compounds in honey $[6,27,29]$. When they come into contact with active ingredients, they react by increasing the uptake of non-contaminated foods and decrease their concentrations of active ingredients in the honey sac $[29,30]$.

Fifth, pesticide concentration was also influenced specific biotransformations, pesticide residues found in one matrix of beehive were not systematically present in the other [31,32]. This explains why some species of neonicotinoid residues found in honey were not similar to those detected in pollen.

Sixth, the sampling period contamination levels were linked to meteorological conditions and were generally higher during dry months. In the present study the sampling at Juja and Thika IPM apiaries was carried out between April-early May and was associated heavy crop treatments with acatamiprid and surprisingly this period coincided with high foraging activity. It absence in other sampled apiaries could be attributed to difference in treatment times.

Acetamiprid in honey was detected at remarkably low levels ranging from 0.10 to $0.50 \mathrm{ppb}$ when compared to its set MRL values (50 ppb); it was far (below) its respective limits established for food products. This clearly indicates the absence of any health risks for the consumers of honey in the region.

\section{Aspects that contribute to presence of thiamethoxam and imidacloprid detected in pollen}

First, nutritional scarcity may influence levels of pesticide residues detected in pollen(beebread); honey bees feed are exposed to residues when they feed on stocked pollen for food reserves especially during dry season. The study was conducted between April-August 2015 which was period of high pesticide use and foraging activity of bees $[33,34]$. Pollen is a major food source for growing bee larvae and nurse workers, and so is a likely source of exposure of bees to neonicotinoids [35]. Systemic introductions of pesticides into pollen may have direct consequences for honey bee health and ultimately lead to pesticide contamination of honey containing food. It has been noted that pollen is of critical importance for foraging bees and food supply of the beehives [36]. Regarding other studies pollen is most contaminated beehive products [6].

Secondly, the contamination of pollen can occur through both contact and oral exposure. According to Williams et al. pollen loads are stocked by bees within the colony in the form of bee bread, a mixture of honey, pollen and several enzymes. When honey bees forage on treated crops, there is a risk of pesticide ingestion [37]. Moreover, bees are often covered with pollen, and other hive matrices mates could be contaminated by topical contact [32]. They could therefore be exposed directly to neonicotinoids when they get into contact with contaminated pollen or bee bread, or indirectly when honey bees feed on the stocked pollen, especially during the dry season $[32,38-40]$.

Thirdly, wide and versatile application and use chemicals. Thiamethoxam is an active ingredient of the widely used plant protection product which is applied as a spray in different crops in the control of pests in flowers, vegetables and maize and bean seed treatment. Imidacloprid was detected in apiaries near crops such as maize, potatoes and vegetables. Beekeepers through survey indicated that they applied the chemicals twice per week and hence frequency of application may also have influenced the concentration levels. However, frequency of application depends on meteorological conditions during the application [34,40].

Fourth, systemic properties of thiamethoxam and imidacloprid. These chemicals can be detected in low levels in pollen and nectar [41] because they are applied in small molecules. Other factors that could have influenced the presence of this chemical in pollen could be the toxic nature of the chemical to bees. Species of neonicotinoid which residues were found could link with bee-toxicities. Thiamethoxam is considered to be highly toxic to honey bees with $\mathrm{LD}_{50}$ of $0.025-0.029$ $\mu \mathrm{g} / \mathrm{bee}$ (USEPA). Its presence in pollen indicates high application of the compound in the field thus honey bees collected the contaminated pollen during foraging activities and transport thiamethoxam into beehives.

Fifth, types of crops treated with chemical around apiaries [42-51]. In this study coffee and horticultural crops were dominant crops that heavily depended on the pesticides. The levels of concentration could also influenced by the size of the plantation. Thiamethoxam, broad spectrum systemic insecticides were used in controlling of sucking insects in flowers, vegetables, leaf miners in coffee plantations [52-59].

\section{Conclusions}

Based on the findings of this study, the conclusion drawn was that neonicotinoid was frequently used by famers in Thika IPM, Thika, Juja, Karura and Kikuyu for controlling pests on horticultural; french beans, pineapples and coffee farms in Kenya. The low levels of neonicotinoids in all honey samples demonstrate that Kenyan honey is safe for human consumption especially from forested landscapes. However, the presence of neonicotinoid residues in beehive products indicate that neonicotinoids is creating a food safety problem in the beekeeping industry hence additional monitoring is necessary. Further studies are also needed to investigate the accumulative effect of these neonicotinoids over time and also hygienic behavior and sensitivity of African honey bees in response to different neonicotinoids levels compared to European bees. 
Citation: Mulati P, Kitur E, Taracha C, Kurgat J, Raina S, et al. (2018) Evaluation of Neonicotinoid Residues in Hive Products from Selected Counties in Kenya. J Environ Anal Toxicol 8: 577. doi: 10.4172/2161-0525.1000577

\section{Acknowledgements}

The authors would like to thank Dr. Rob Skilton, Dr. Chris Beadle and Dr. Peter Willadsen for their tremendous help and useful comments during the manuscript write-up, colleagues from African Reference Laboratory Bee Health (ARLBH) a ICIPE for their support. Special thanks to James Ng'ang'a, and various beekeepers in Kenya for their support during sample collection. This work has been supported financially by the European Union grant number DCI-FOOD-2013/313-659.

\section{References}

1. Fairbrother A, Purdy J, Anderson T, Fell R (2014) Risks of neonicotinoid insecticides to honeybees. Environmental Toxicology and Chemistry 33: 719-731.

2. Williams GR, Tarpy DR, van Engelsdorp D, Chauzat MP, Cox-Foster DL (2010) Colony Collapse Disorder in context. BioEssays 32: 845-846.

3. EU Regulation (EU) No 485/2013 (2013) Official Journal of the European Union 139: 12-26.

4. Whitehorn P, O'connor S, Wackers F, Goulson D (2012) Neonicotinoid Pesticides Reduces Bee Colony Growth and Queen Production. Science 336: 351-352.

5. Williamson S (2003) The dependency syndrome: Pesticide use by African small holders: A report for PAN-UK's Pesticide Poverty and Livelihoods Project. Pest Action Network.

6. Bogdanov S (2006) Contaminants of Bee Products. Apidologie 37: 1-18.

7. de Pinho GP, Neves AA, de Queiroz ME, Silvério FO (2010) Optimization of the liquid- liquid extraction method at low temperature purification(LLE-LTP) for pesticide residue analysis in honey samples by gas-chromatography. Food Control 21: 1307-1311.

8. Irani M (2009) Determination of pesticides residues in honey samples. Bul Environ Contam Toxicol 83: 818-821.

9. Blasco C, Vazquez-Roig P, Onghena M, Masia A, Pico Y (2011) Analysis of insecticides in honey by liquid chromatogrpahy-ion trap mass spectrometry: comparison of different extraction procedures. J Chromato A 1218: 4892-4901.

10. Weist L, Bulete A, Giroud B, Fratta C, Amic S, et al. (2011) Multiresidue analysis of 80 environmental contaminants in honeys, honeybees and pollens by one extraction procedure followed by liquid and gas chromatography coupled with mass spectrometric detection. J Chromatogr A 1218: 5743.

11. Kujawski MW, Namiesnik J (2011) Levels of 13 multi-class pesticide residues in Polish honeys determined by LC-ESI-MS/MS. Food Control 22: 914-919.

12. Wang J, Kliks MM, Jun S, Li QX (2010) Residues of organochlorine pesticides in honeys from different geographical regions. Food Res Int 43: 2329-2334.

13. Campillo N, Penalver R, Aguinaga N, Hernandez-Cordoba M (2006) Solidphase microextraction and gas chromatography with atomic emission detection for multiresidue determination of pesticides in honey. Anal Chim Acta 562: 9-15.

14. Choudhary A, Sharma D (2008) Dynamic of pesticide residues in nectar and pollen of mustard (Brassica jucea) (L) Czern growing in Himachal Pradesh (India). Environmental Monitoring and Assessment 144: 143-150.

15. Martel AC, Zeggane S, Aurieres C, Drajnudel P, Faucon JP, et al. (2007) Acaricide residues in honey and wax after treatment of honey bee colonies with Apivar or Asuntol50. Apidologie 38: 534-544.

16. Erdogrul $O$ (2007) Levels of selected pesticides in honey samples from Kahramanmaras, Turkey. Food Control 18: 866-871.

17. Blasco C, Fernadez M, Pena A, Lino C, Silveria M (2003) Assessment of Pesticide Residues in honey samples from Portugal and Spain. Journal of Agriculture and Food Chemistry 51: 225- 238.

18. Eissa F, El-Sawi S, Zidan NE (2014) Determining pesticide residues in honey and their potential risk to consumers. Pol J Environ Stud 23: 1573-1580.

19. Irungu J, Protus AT, Nkoba MJ, Raina S (2016) Analysis of honey bee hive products as a model for monitoring pesticide usage in agroecosystems. Analysis 6: 9-16.

20. Irungu J, Raina S, Torto B (2016) Determination of pesticide residues in honey: a preliminary study from two of Africa's largest honey producers. International Journal of Food Contamination 3: 14.

21. Gitonga ZM, Okelo J, Mithofa D, Olaye CA, Rilto C (2011) Control of invasive liriomyza leafminus and compliance with food safety standards in Kenya's snow pea industry. Journal of Agricultural Economics 14: 2-4.
22. Ntow J (2008) The use and fate of pesticides in tomato based AgroEcosystemsin Ghana. PhD Thesis, Wageningen University, The Netherlands.

23. Tomlin C (1994) A World compendium. The pesticide manual incorporating the agrochemicals handbook. 10th edn. Bungay, Suffolk, UK. Crop Protection Publications.

24. WHO (1986) A report on the International Programme on Chemical Safety Geneva.

25. Macharia I, Mithofer D, Waibel H (2009) Potential Environmental Impacts of Pesticide use in the vegetable sub-section in Kenya. African Journal of Horticultural Sciences 2: 138-151.

26. Henry M, Beguin M, Requier F, Rollin O, Odoux J, et al. (2012) Response to comment on "A common Pesticide Decreases Foraging Success and Survival in Honey bees". Science 337: 1453-1455.

27. Klein A, Brittain C, Hendrix S, Thorp R, William N (2012) Wild pollination services to California Almond rely on semi-natural habitat. Journal of Applied Ecology 49: 723-732.

28. Mullin C, Frazier J, Ascraft S, Siminds R (2010) High levels of miticides and agrochemicals in North American Apiaries: Implications for honey be health. PLoS ONE 5: e9754.

29. Thompson H, Harrington P, Wilkins S, Pietravalle S, Sweet D (2013) Effects of neonicotinoids seed treatments on bumble bee colonies under field conditions. I. Preparation.

30. Bogdanov S, Imdorf A, Charriere J, Fluri P, Kilchenmann V (2003) The contaminants of the bee colony. Swiss Bee Research Centre, Bern, Switzerland 99: 8-12.

31. Decourtye A, Devillers J, Cluzeau S, Charreton M, Pham-Delegue M (2004) Effects of imdidacloprid and Deltamethrin on associative learning in honey bees under semi-field and laboratory conditions. Ecotoxicology and Environmental Safety 57: 410-419.

32. Bonmatin JM, Monineau I, Charvet R, Fleche C, Colin ME (2003) LC/APCIMS/MS method for analysis of imidacloprid in soils, in plants and in pollens. Analytical Chemistry 75: 2027-2033.

33. Ghini S, Fernandez M, Pico Y, Marin R, Fini F, et al. (2004) Occurrence and distribution of pesticides in the province of Bologna, Italy, using honeybees as bioindicators. Archives of Environmental Contamination and Toxicology 47: 479-488.

34. Krupke CH, Hunt GJ, Eitzer BD, Andino G, Given K (2012) Multiple routes of Pesticide exposure for honey Bees living near agricultural Fields. PLoS ONE 7: e29268.

35. Sanchez-Bayo F, Goka K (2014) Pesticide residues and bees-a risk assessment. PLoS ONE 94482: 1-16.

36. Kaskoniene V, Venskutonis PR, Ceksteryte V (2010) Carbohydrate composition and electrical conductivity of different origins honeys from Lithuana. LWT-Food Science Technology 45: 801-807

37. Halm MP, Rortais A, Arnold G, Taséi JN, Rault S (2006) New risk assessment approach for systemic insecticides: the case of honey bees and imidacloprid (Gaucho). Environmental Science \& Technology 40: 2448-2454.

38. Nguyen B, Pirard C, Haubrudge E, Wildart J, Saegerman C, et al. (2009) Development and validation of a multi-residue method for pesticide determination in honey using honey using on column liquid-liquid extraction and liquid chromatography-tandem mass spectrometry. Journal of Chromatography A 1152: 116-123.

39. Lambert O, Veyrand B, Durand S, Marchand P, Le Bizec B (2012) Polycyclic aromatic hydrocarbons: bees, honey and pollen as sentinels for environmental chemical contaminants. Chemosphere 86: 98-104.

40. Hopwood J, Vaughn M, Shepherd M, Biddiger E, Blacks S, et al. (2012) Are neonicotinoids killing bees? A review of research into the effects of neonicotinoids on bees with recommendations for actions. Xercess Society for Invertebrate Conservation, p: 32.

41. Al-Waili N, Salom K, Al-Ghamdi A, Ansari MJ (2012) Antibiotic, pesticide, and microbial contaminants of honey: human health hazards. Sci World J 2012: 1-9.

42. Bommarco R, Biesmejier JB, Poyey J, Roberts S (2010) Dispersal Capacity and Diet Breadth modify the response of wild bees to habitat loss. Proceedings of the Royal Society B: Biological Sciences 277: 2075-2082. 
Citation: Mulati P, Kitur E, Taracha C, Kurgat J, Raina S, et al. (2018) Evaluation of Neonicotinoid Residues in Hive Products from Selected Counties in Kenya. J Environ Anal Toxicol 8: 577. doi: 10.4172/2161-0525.1000577

43. Bonmattin J, Moineau I, Charvet R, Colin M, Fleche C et al. (2005) Behaviour of Imidacloprid in fields. Toxicology for Honey bees in Environmental Chemistry. Berlin, Germany.

44. Formato G, Zilli R, Condoleo R, Marozzi S, Davis I, et al. (2011) Risk management in primary apicultural production. Part 2: A Hazard Analysis Critical Control Point approach to assuring the safety of unprocessed honey. Veterinary Quarterly 31: 87-97.

45. Anonymous. Critical control point approach to assuring the safety of unprocessed honey. The Veterinary Quarterly 31: 87-97.

46. Gitonga W, Macharia J, Mungai A, Njue H, Kanja D, et al. (2010) Cotton Production Constraints and Research Intervention in Kenya. Nairobi: Government of Kenya.

47. Gitonga ZM, Okelo J, Mithofa D, Chabi Olaye A, Rilto C (2010) Control of invasive Liriomyza leafminers and compliance with food safety standards in Kenya's snow pea industry. Journal of Agricultural Economics 14: 2-4.

48. Jeschke P, Nauen R, Schindler M, Elbert A (2010) Overview of the status and global strategy for neonicotinoids. Journal of Agricultural and Food Chemistry 59: 2897-2908.

49. Kievits J (2007) Bees gone: Colapse disorder. Pesticide News 76: 3-5.

50. Kujawski M, Namiesnik $\mathrm{J}(2008)$ Challenges in preparing honey samples from chromatographic determination of contaminants abd trace residues. TRAC Trends in Analytical Chemistry 27: 785-793.

51. Mommaerts V, Reynders R, Boulet J, Bessard L, Sterk G, et al. (2010) Risk Assessment for side effects of neonicotinoids against bumblebees with and without imparing foraging behaviour. Ecotoxicology 19: 207-215.
52. Muli E, Patch H, Frazier J, Kimani J, Mumoki J, et al. (2014) Evaluation of the distribution and impacts of parasites, pathogens and pesticides on honey bee (Apis mellifera) populations in East Africa. PLoS ONE, pp: 4-9.

53. Perrugin M, Manera M, Grotta L, Abete M, Tarasco R (2011) Heavy metals ( $\mathrm{Hg}$ $\mathrm{Cr}, \mathrm{Cd}$ and $\mathrm{Pb}$ ) Contamination in urban environment. Environmental Monitoring and Assessment 138: 233-238.

54. Pohorecka K, Skubida P, Miszczak A, Semkiw P, Sikorski P (2012) Residues of Necotinoid insecticides in bee collected plant materials from oil seed rape crops and their effects on bee Colonies. Journal of Apicultural Science 56: 115-134.

55. Rortais A (2005) Modes of honeybee's exposure to systemic insecticides: estimated amounts of contaminated pollen and nectar consumed by different categories of bees. Apidolgie 36: 71-83.

56. SANCO (2013) Guidance document on analytical quality control and validation procedures for pesticide residues analysis in food and feed. Brusells: European Union.

57. Thompson HM, Hunt L (1999) Extrapolating from Honey bees to bumblebees in pesticide risk assessment. Ecotoxicology 8: 147-166.

58. UNEP (2010) The Global Honey bee colony disorder and other threats to insects Pollinators. Agriculture United Environment Programme.

59. Waichman A, Eve E, Nina N (2007) Do farmers understand information displayed on pesticides product labels? A key question to reduce pesticide exposure and risk poisoning in the Brazilian Amazon. Crop Protection, pp: 576583. 